\title{
BMJ Open Predictors of unrecognised comorbid depression in patients with schizophrenia at Amanuel mental specialized hospital, Ethiopia: a cross- sectional study
}

\author{
Mohammed Ayalew (D) , ${ }^{1}$ Yared Reta (D) , ${ }^{1}$ Semira Defar ${ }^{2}$
}

To cite: Ayalew M, Reta Y, Defar S. Predictors of unrecognised comorbid depression in patients with schizophrenia at Amanuel mental specialized hospital, Ethiopia: a crosssectional study. BMJ Open 2021;11:e049026. doi:10.1136/ bmjopen-2021-049026

- Prepublication history for this paper is available online. To view these files, please visit the journal online (http://dx.doi org/10.1136/bmjopen-2021049026).

Received 25 January 2021 Accepted 06 September 2021

D) Check for updates

(c) Author(s) (or their employer(s)) 2021. Re-use permitted under CC BY-NC. No commercial re-use. See rights and permissions. Published by BMJ.

${ }^{1}$ School of Nursing, Hawassa University College of Medicine and Health Sciences, Hawassa, Ethiopia

${ }^{2}$ Department Midwifery, Hawassa University College of Medicine and Health Sciences, Hawassa, Ethiopia

Correspondence to Mr Mohammed Ayalew; mameayale@gmail.com

\section{ABSTRACT}

Background The occurrence of depression in patients with schizophrenia (PWS) increases the risk of relapse, frequency and duration of hospitalisation, and decreases social and occupational functioning.

Objective This study aimed to assess prevalence of unrecognised comorbid depression and its determinants in PWS.

Method A cross-sectional study was conducted from 1 to 30 March 2019 at Amanuel mental specialized hospital among 300 PWS. The 9-item Calgary Depression Scale for Schizophrenia was used to assess comorbid depression. Logistic regression was used to determine the association between outcome and explanatory variables. Statistical significance was declared at $p$ value $<0.05$ with $95 \% \mathrm{Cl}$. Results The prevalence of unrecognised comorbid depression was found to be $30.3 \%$. Living alone (adjusted $\mathrm{OR}(\mathrm{AOR})=3.49,95 \% \mathrm{Cl}=0.45$ to 8.36$)$, having poor (AOR=4.43, 95\% $\mathrm{Cl}=1.45$ to 13.58 ) and moderate ( $\mathrm{AOR}=4.45,95 \% \mathrm{Cl}=1.30$ to 15.22 ) social support, nonadherence to medication ( $\mathrm{AOR}=3.82,95 \% \mathrm{Cl}=1.70$ to 8.55), presenting with current negative symptoms such as asocialia ( $\mathrm{AOR}=4.33,95 \% \mathrm{Cl}=1.98$ to 9.45$)$ and loss of personal motivation ( $\mathrm{AOR}=3.46,95 \% \mathrm{Cl}=1.53$ to 7.84 ), and having suicidal behaviour $(\mathrm{AOR}=6.83,95 \% \mathrm{Cl}=3.24$ to 14.41) were the significant predictors of comorbid depression in PWS.

Conclusion This study revealed considerably a high prevalence of unrecognised comorbid depression among PWS. Therefore, clinicians consider timely screening and treating of comorbid depression in PWS.

\section{INTRODUCTION}

Both schizophrenia and depression are the most overwhelming psychiatric illnesses that have substantial contribution to the global burden of disease. ${ }^{1-3}$ Besides, patients with schizophrenia (PWS) have an increased risk of developing depressive symptoms compared with the general population. ${ }^{4}$ During the course of their illness, majority of PWS show depressive symptoms ${ }^{5}$ and therefore,
Strengths and limitations of this study

- The main strength of this study is we use a standardised tool (Calgary Depression Scale for Schizophrenia (CDSS)) designed to assess depression in patients with schizophrenia (PWS).

- Exclusion of patients who were on antidepressant medications and studying only PWS in outpatients could have led to an underestimation of the prevalence of depression.

- Our study was a cross-sectional design that does not show cause and effect relationship.

- Using non-probability consecutive sampling method and small sample size also might be considered as limitation.

- Even though we use internationally validated instrument to assess depression, CDSS was not yet validated in Ethiopia.

depressive symptoms are an important part of schizophrenia. ${ }^{6}$

PWS develop depressive symptoms anytime during the course of the illness that is, either in the prodrome of a new episode, concurrently with the acute episode or in the post-psychotic period. $^{7}$ However, negative symptoms in schizophrenia that are similar to those in depression such as apathy, lack of emotion or poor social functioning reflect a decrease in the level of normal functions. ${ }^{8}$ In addition, extra-pyramidal side effects, developing in relation with antipsychotic drugs, complicate the diagnosis of depression among PWS. ${ }^{9}$ Therefore, the occurrence of depression in PWS complicates the diagnosis and treatment process.

Co-occurrence of depression in PWS also affects the prognosis of the disease. This further increases the risk of relapse, frequency and duration of hospitalisation, and decreases social and occupational functioning. ${ }^{10}$ The 
Table 1 Sociodemographic characteristics of patients that participate on study of predictors of unrecognised depression in PWS at AMSH, 2019

\begin{tabular}{|c|c|c|c|c|}
\hline S.No & Variable & Categories & Frequency & $\begin{array}{l}\text { Percentage } \\
(\%)\end{array}$ \\
\hline \multirow[t]{4}{*}{1} & \multirow[t]{4}{*}{ Age } & $18-27$ & 60 & 20.0 \\
\hline & & $28-37$ & 116 & 38.7 \\
\hline & & $38-47$ & 82 & 27.3 \\
\hline & & $\geq 48$ & 42 & 14.0 \\
\hline \multirow[t]{2}{*}{2} & \multirow[t]{2}{*}{ Sex } & Male & 203 & 67.7 \\
\hline & & Female & 97 & 32.3 \\
\hline \multirow[t]{3}{*}{3} & \multirow{3}{*}{$\begin{array}{l}\text { Marital } \\
\text { status }\end{array}$} & Single & 179 & 59.7 \\
\hline & & Married & 92 & 30.7 \\
\hline & & Divorced & 29 & 9.6 \\
\hline \multirow[t]{4}{*}{4} & \multirow[t]{4}{*}{ Religion } & Muslim & 99 & 33 \\
\hline & & Orthodox & 148 & 49.3 \\
\hline & & Protestant & 46 & 15.3 \\
\hline & & Others & 7 & 2.3 \\
\hline \multirow[t]{4}{*}{5} & \multirow{4}{*}{$\begin{array}{l}\text { Educational } \\
\text { status }\end{array}$} & Illiterate & 70 & 23.4 \\
\hline & & $1-8$ th grade & 75 & 25 \\
\hline & & $9-12$ th grade & 122 & 40.7 \\
\hline & & $\begin{array}{l}\text { College and } \\
\text { above }\end{array}$ & 33 & 11 \\
\hline \multirow[t]{2}{*}{6} & \multirow[t]{2}{*}{ Occupation } & Employed & 62 & 20.7 \\
\hline & & Unemployed & 238 & 79.3 \\
\hline \multirow[t]{2}{*}{7} & \multirow{2}{*}{$\begin{array}{l}\text { Average } \\
\text { monthly } \\
\text { income }\end{array}$} & $\leq$ US\$18.4 & 201 & 67 \\
\hline & & $\geq$ US\$18.5 & 99 & 33 \\
\hline \multirow[t]{2}{*}{8} & \multirow{2}{*}{$\begin{array}{l}\text { Place of } \\
\text { residence }\end{array}$} & Rural & 78 & 26 \\
\hline & & Urban & 222 & 74 \\
\hline \multirow[t]{2}{*}{9} & \multirow{2}{*}{$\begin{array}{l}\text { Living } \\
\text { status }\end{array}$} & With family & 244 & 81.3 \\
\hline & & Alone & 56 & 18.7 \\
\hline
\end{tabular}

AMSH, Amanuel mental specialised hospital; PWS, patients with schizophrenia.

expected lifespan of PWS could be reduced by an average of 10-15 years, and suicide is the leading cause of this premature death among PWS. ${ }^{11}$ More than half of PWS attempts suicide and 9\%-13\% completed suicide in their lifetime, ${ }^{11}{ }^{12}$ which could be more complicated and severe with presence of depression. Furthermore, emerging depressive symptoms are associated with impairment in everyday functioning, poorer quality of life, substance abuse and weak response to pharmacological treatment. ${ }^{13}$

A review of previous studies reported that prevalence of comorbidity of depression among PWS is $7 \%-75 \%,{ }^{14}$ but on average, depression is observed in one out of four patients. ${ }^{15} 16$ Depressed mood is commonly associated with first and acute psychotic episodes of PWS. ${ }^{17}$ However, one-third of PWS reported depressive symptoms several months after the remission of a psychotic episode, recently termed 'post-psychotic depression'. ${ }^{18}$ Studies reported that $25 \%$ of PWS developed post-psychotic depression ${ }^{19}$ and more than $80 \%$ of patients with first episode psychosis did suffer from depressed mood. ${ }^{14}$ Moreover, reports from longitudinal studies indicate that depressive symptoms have found to be prevalent during all stages of schizophrenia. ${ }^{20}$

Depressive symptoms in PWS could be associated with responses to psychological stress or deficits, ${ }^{21}$ undesired side-effects of antipsychotics medications, ${ }^{22}$ substance or drug abuse ${ }^{23}$ and other organic or physical illnesses. ${ }^{24}$ Furthermore, social isolation, loss, unemployment, financial difficulties, adverse life events and stigma are some of the factors that are associated with depression in schizophrenia. ${ }^{25}$

Yet, depressive symptoms that occur in PWS are often overlooked, inadequately characterised and not consistently integrated into treatment. ${ }^{25}$ Therefore, recognising depressive symptoms or episodes in PWS may promote the pharmacological treatment of depressive episodes and thus prevent subsequent suicide attempts or suicide. Therefore, the aim of this study was to assess the magnitude of unrecognised comorbid depression and predicting factors among PWS.

The present study is among the first in our community to underscore the hypothesis that depression is an important clinical phenomenon in schizophrenia. The most striking finding of this study is that it alerts mental health professionals about the unrecognised depressive symptoms in PWS.

\section{METHODS \\ Ethics statement}

The Institutional Review Board of Hawassa University, College of Medicine and Health Sciences approved the study and written informed consent was received from all participants.

\section{Study design, area and period}

From 1 to 30 March 2019, an institution-based crosssectional study was conducted at Amanuel mental specialized hospital (AMSH) in Addis Ababa, Ethiopia. The hospital is one of the oldest in Ethiopia, having been founded in 1930 E.C. during the Ethio-Italian war, and it is the country's only mental hospital. Each year, approximately 46520 patients with psychiatric disorders visit as outpatients, and approximately 160 patients are admitted to the ward each month. The hospital has over 300 beds and serves patients with all types of mental disorders. There are 13 outpatient departments (OPDs) at the hospital. The hospital also serves as a teaching facility and a research facility for mental health sciences.

\section{Population}

All PWS who had a follow-up visit at AMSH belonged to the source population. The study population consisted 
Table 2 Clinical characteristics of PWS at AMSH, 2019

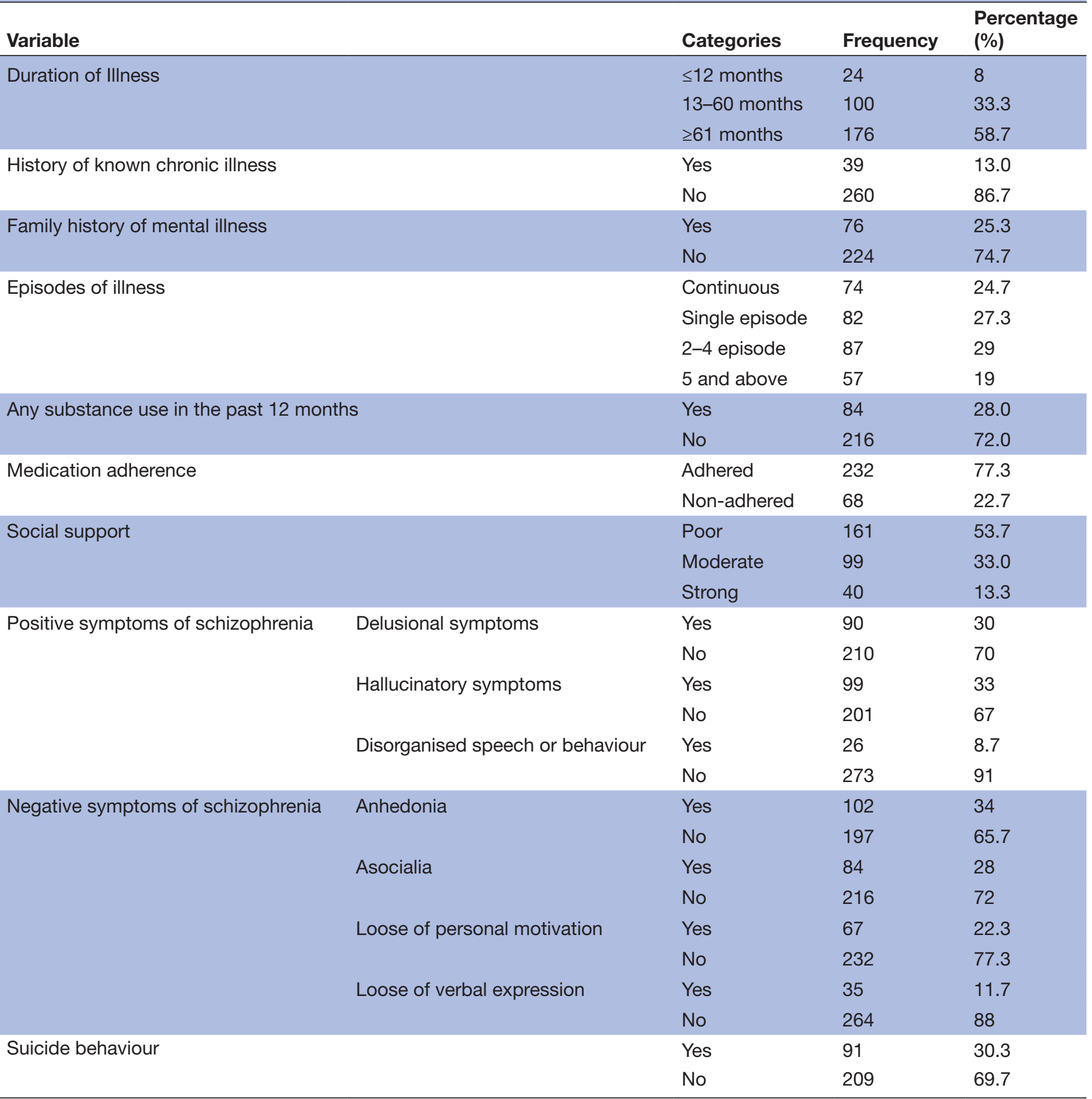

AMSH, Amanuel mental specialized hospital; PWS, patients with schizophrenia.

of all sampled PWS who had a follow-up visit at AMSH during the study period and met the inclusion criteria.

\section{Inclusion and exclusion criteria}

PWS who were 18 years or older were included in the study. PWS who were experiencing severe acute psychotic episodes and were unable to communicate were, however, excluded from the study. Clinical Global Impression Severity (CGI-S) Scale with seven-point scale was used to assess the severity of the psychotic episode. The CGI-S scale ranges from 1 (normal) to 7 (among the most seriously ill).$^{26}$ Patients with a CGI-S score of 6 or higher were excluded from the study. Patients who were on antidepressant medication were also excluded.

\section{Sample size determination and sampling technique}

Using the consecutive sampling technique, 300 PWS were chosen from the AMSH OPD. PWS who visited psychiatry OPD during the study period and met the inclusion 


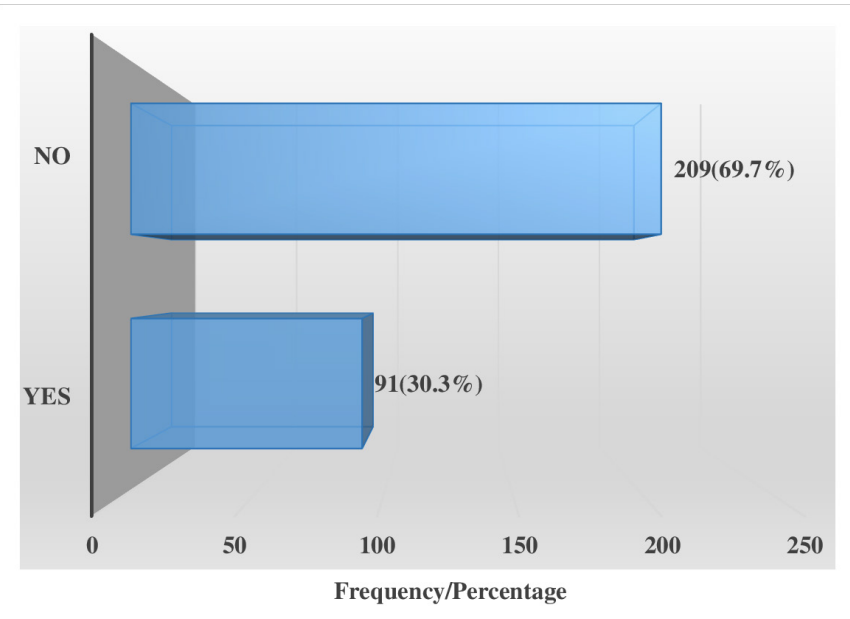

Figure 1 Comorbid depression in PWS at AMSH Addis Ababa, Ethiopia, 2019. AMSH, Amanuel mental specialized hospital; PWS, patients with schizophrenia.

criteria were enrolled until the final study sample size was reached.

\section{Data collection tools and quality assurance}

A structured questionnaire administered by an interviewer was used to collect data. The questionnaire is divided into six sections: part one includes questions about patients' sociodemographic characteristics and related factors; part two includes questions about patient clinical characteristics; part three is about patient social support; part four is about medication adherence; part five is about patients' suicidal behaviour and part six is about depression screening. Psychiatrists, psychiatry residents and senior or expert mental health professionals made patient diagnoses based on Diagnostic Statistical Manual for Mental Disorders-5 diagnostic criteria.

The Calgary Depression Scale for Schizophrenia (CDSS) was used to assess the change in the level and intensity of unrecognised depressive symptoms in schizophrenia. It consists of nine items scored on a Likert scale $(0=$ absent, $1=$ mild, $2=$ moderate and $3=$ severe $)$. The lowest possible score is 0 and the highest possible score is $27{ }^{27}$ A CDSS score of more than 6 points has been proposed to distinguish PWS with depression from those who do not. $^{28}$

The level of social support among PWS was measured using the three-item Oslo Social Support Scale, with scores ranging from 3 to $14 .^{29}$ To assess medication adherence in PWS, a four-item questionnaire adapted from a previous study was used. The four items have a scoring scheme of 'Yes' $=0$ and 'No' $=1$. The items are added up to give a score from 0 to 4 , with 1 being adhered and 2 being non-adhered. ${ }^{30}$

To evaluate suicidal behaviour the Suicidal Behaviour Questionnaire Revised (SBQ-R) with four items was used. SBQ-R item 1 assesses lifetime suicidal ideation and attempt; item 2 evaluates the frequency of suicidal ideation over the previous 12 months; item 3 assesses the threat of suicidal behaviour and item 4 assesses self-reported likelihood of suicidal behaviour. With a score of 3-18 and a cut-off point of 8 , the sensitivity was $80 \%$ and the specificity was $91 \%$ for the adult clinical population. ${ }^{31}$

To ensure the tool's consistency and understandability, an independent person translated the English version questionnaire into Amharic and then back into English. Language experts were brought in to help with the translation of the questionnaire. The information was gathered by psychiatry nurses who were overseen by expert mental health professionals. Data collectors and supervisors were both given training. Before the main study, a pre-test on $5 \%$ of the study sample size was conducted at AMSH among PWS in the psychiatric ward to identify potential problems with data collection instruments, as well as to check the consistency of the questionnaires and the performance of the data collectors. Aside from that, the data collectors were supervised daily, and the completed questionnaires were checked daily by the supervisors and principal investigator.

\section{Data processing and analysis}

Before beginning analysis, the collected data were checked, coded and entered into Epi-data V.3.1 to minimise errors during data entry; the data were then exported to SPSS V.20 for cleaning and analysis. The sociodemographic and clinical characteristics of the patients were analysed using descriptive statistics, that is, frequencies and percentages were calculated for categorical variables. For each independent variable, an independent bivariate logistic regression analysis was performed against the dependent variable or CDSS. Variables with a $\mathrm{p}$ value of $<0.05$ were considered as candidates for multiple logistic regression to determine the variables that independently predict depression in simple binary logistic regression analysis. The multivariate analysis results were presented as crude and adjusted ORs. In multivariate logistic regression analysis, a $\mathrm{p}$ value of $<0.05$ was declared statistically significant at the $95 \%$ CI. Finally, the study's findings were summarised using tables, graphs and narrative descriptions.

\section{Patients and public involvement}

Patients and the public were not involved in this study, including the recruitment, data collection, analysis, interpretation and dissemination of the results.

\section{RESULTS}

Sociodemographic and clinical characteristic of participants The study included 300 PWS. More than two-thirds (203, $67.7 \%)$ of the participants were men, and $116(38.7 \%)$ participants were between the age of 28 and 37 years. The majority of the participants $(179(59.7 \%))$ were single, $238(79.3 \%)$ of the study participants were unemployed and $257(85.7 \%)$ were living with their family (table 1$)$. 
Table 3 Bivariate analyses of risk factors for unrecognised depression in PWS at AMSH, 2019

\begin{tabular}{|c|c|c|c|c|c|}
\hline \multirow[b]{2}{*}{ Variables } & \multirow[b]{2}{*}{ Category } & \multicolumn{2}{|l|}{ Depression } & \multirow{2}{*}{$\begin{array}{l}\text { COR } \\
\text { OR }(95 \% \mathrm{Cl})\end{array}$} & \multirow[b]{2}{*}{$P$ value } \\
\hline & & No & Yes & & \\
\hline \multirow[t]{3}{*}{ Age } & $18-27$ & 39 (74.6\%) & $21(25.6 \%)$ & 1 & \\
\hline & $38-47$ & $58(70.4 \%)$ & $24(29.6 \%)$ & $0.768(0.377$ to 1.567$)$ & 0.469 \\
\hline & $\geq 48$ & 25 (59.5\%) & $17(40.5 \%)$ & $1.263(0.560$ to 2.847$)$ & 0.574 \\
\hline Sex & Female & 74 (33.3\%) & $23(26.7 \%)$ & $0.617(0.356$ to 1.071$)$ & 0.086 \\
\hline \multirow[t]{3}{*}{ Marital status } & Single & $127(71.0 \%)$ & $52(29.0 \%)$ & 1 & \\
\hline & Married & $63(68.4 \%)$ & 29 (31.6\%) & $1.124(0.652$ to 1.940$)$ & 0.674 \\
\hline & Divorced & $19(65.5 \%)$ & $10(34.5 \%)$ & $1.285(0.560$ to 2.951$)$ & 0.554 \\
\hline Educational status & Illiterate & $52(74.2 \%)$ & $18(25.8 \%)$ & $0.368(0.154$ to 0.876$)$ & 0.024 \\
\hline \multirow[t]{2}{*}{ Occupational status } & Employed & $39(62.9 \%)$ & $23(37.1 \%)$ & 1 & \\
\hline & Unemployed & $170(71.2 \%)$ & $68(28.8 \%)$ & $0.678(0.377$ to 1.220$)$ & 0.195 \\
\hline \multirow[t]{2}{*}{ Area of residence } & Rural & $51(65.3 \%)$ & $27(34.7 \%)$ & 1 & \\
\hline & Urban & $158((71.1 \%)$ & $64(28.9 \%)$ & $0.765(0.442$ to 1.325$)$ & 0.340 \\
\hline \multirow[t]{2}{*}{ Living status } & With family & $186(72.3 \%)$ & $58(23.7 \%)$ & 1 & \\
\hline & Alone & $23(41.1 \%)$ & $33(58.9 \%)$ & 4.601 (2.504 to 8.456$)$ & $<0.001$ \\
\hline \multirow[t]{2}{*}{ Duration of illness } & $\leq 12$ months & $15(62.5 \%)$ & $9(37.5 \%)$ & 1 & \\
\hline & 13-60 months & $76(76.0 \%)$ & $24(24.0 \%)$ & $0.526(0.205$ to 1.354$)$ & 0.183 \\
\hline \multirow{3}{*}{ Episodes of illness } & Single episode & $60(73.1 \%)$ & $22(28.9 \%)$ & 0.925 (0.458 to 1.869$)$ & 0.829 \\
\hline & 2-4 episode & $57(65.5 \%)$ & $30(34.5 \%)$ & 1.328 (0.679 to 2.600$)$ & 0.407 \\
\hline & 5 and above & $39(68.4 \%)$ & $18(31.6 \%)$ & 1.165 (0.548 to 2.474$)$ & 0.691 \\
\hline \multirow[t]{2}{*}{ Substance use } & Yes & $55(65.4 \%)$ & $29(34.5 \%)$ & $1.310(0.765$ to 2.242$)$ & 0.325 \\
\hline & No & $154(71.2 \%)$ & $62(28.8 \%)$ & 1 & \\
\hline \multirow[t]{3}{*}{ Social support } & Poor & $101(62.7 \%)$ & $60(37.3 \%)$ & 2.801 (1.166 to 6.724$)$ & 0.021 \\
\hline & Moderate & $75(75.8 \%)$ & $24(24.2 \%)$ & 1.509 (0.592 to 3.847$)$ & 0.389 \\
\hline & Strong & $33(82.5 \%)$ & $7(17.5 \%)$ & 1 & \\
\hline \multirow[t]{2}{*}{ Medication adherence } & Adhered & $175(75.4 \%)$ & $57(24.6 \%)$ & 1 & \\
\hline & Non-adhered & $34(50.0 \%)$ & $34(50.0 \%)$ & 3.070 (1.751 to 5.383$)$ & $<0.001$ \\
\hline \multirow[t]{2}{*}{ Hallucination } & Yes & $58(58.5 \%)$ & $41(41.5 \%)$ & 2.135 (1.279 to 3.562$)$ & 0.004 \\
\hline & No & $151(75.1 \%)$ & $50(24.9 \%)$ & 1 & \\
\hline \multirow[t]{2}{*}{ Delusion } & Yes & $49(54.4 \%)$ & $41(45.6 \%)$ & 2.678 (1.588 to 4.515$)$ & $<0.001$ \\
\hline & No & $160(76.1 \%)$ & $50(23.9 \%)$ & 1 & \\
\hline \multirow[t]{2}{*}{ Disorganised speech } & Yes & $9(33.3 \%)$ & $18(66.7 \%)$ & $5.479(2.356$ to 12.741$)$ & $<0.001$ \\
\hline & No & $200(73.2 \%)$ & 73 (26.8\%) & 1 & \\
\hline
\end{tabular}


Table 3 Continued

\begin{tabular}{|c|c|c|c|c|c|}
\hline \multirow[b]{2}{*}{ Variables } & \multirow[b]{2}{*}{ Category } & \multicolumn{2}{|l|}{ Depression } & \multirow{2}{*}{$\begin{array}{l}\text { COR } \\
\text { OR }(95 \% \mathrm{Cl})\end{array}$} & \multirow[b]{2}{*}{$P$ value } \\
\hline & & No & Yes & & \\
\hline \multirow[t]{2}{*}{ Anhedonia } & Yes & $55(53.3 \%)$ & $48(46.7 \%)$ & 3.126 (1.869 to 5.226$)$ & $<0.001$ \\
\hline & No & $154(78.1 \%)$ & $43(21.9 \%)$ & 1 & \\
\hline \multirow[t]{2}{*}{ Asocialia } & Yes & $38(45.2 \%)$ & $46(54.8 \%)$ & 4.600 (2.679 to 7.900$)$ & $<0.001$ \\
\hline & No & $171(79.1 \%)$ & 45 (20.9\%) & 1 & \\
\hline \multirow[t]{2}{*}{ Loss of personal motivation } & Yes & $27(39.7 \%)$ & $41(60.3 \%)$ & 5.527 (3.101 to 9.851$)$ & $<0.001$ \\
\hline & No & $182(78.4 \%)$ & $50(21.6 \%)$ & 1 & \\
\hline \multirow[t]{2}{*}{ Alogia } & Yes & $18(50.0 \%)$ & $18(50.0 \%)$ & 2.616 (1.290 to 5.305$)$ & 0.008 \\
\hline & No & $191(72.3 \%)$ & $73(27.7 \%)$ & & \\
\hline \multirow[t]{2}{*}{ Suicide behaviour } & Yes & $38(41.7 \%)$ & $53(58.3 \%)$ & $0.159(0.092$ to 0.275$)$ & $<0.001$ \\
\hline & No & 171 (81.8\%) & 38 (18.2\%) & 1 & \\
\hline
\end{tabular}

AMSH, Amanuel mental specialized hospital; COR, crude OR; PWS, patients with schizophrenia.

\section{Clinical characteristic of study participants}

Majority of all participants (176 (58.7\%)) have had their illness for more than 5 years, and $84(28 \%)$ have used at least one type of substance in the previous 12 months. Among the most common symptoms hallucination and anhedonia, which affect one-third of the participants 99 $(33 \%)$ and $102(34 \%)$, respectively. Approximately half of the study participants (161 (53.7\%)) had a poor social support, and 91 (30.3\%) had suicide behaviour (table 2).

\section{Magnitude of comorbid depression among patients with schizophrenia}

Among 300 PWS, 91 (30.3\%) have unrecognised comorbid depression according to CDSS (figure 1).

\section{Independent predictors of unrecognised depression}

Educational status, living status, known history of chronic medical illness, level of social support, medication adherence, positive symptoms (hallucination, delusion and disorganised speech), negative symptoms (anhedonia, asocialia, loss of personal motivation and alogia) and suicide behaviour are among the many variables that run in bivariate logistic regression analyses and become candidates for multiple logistic regression analysis at $\mathrm{p}$ value $<0.05$ (table 3 ).

Finally, in multivariate logistic regression model, living alone ( $\mathrm{AOR}=3.488,95 \% \mathrm{CI}=0.455$ to 8.363$)$, having poor $(\mathrm{AOR}=4.434,95 \% \mathrm{CI}=1.448$ to 13.581$)$ and moderate $(\mathrm{AOR}=4.447,95 \% \mathrm{CI}=1.299$ to 15.221$)$ social support, non-adherence to medication $(\mathrm{AOR}=3.815$, $95 \% \mathrm{CI}=1.702$ to 8.551$)$, presenting with current negative symptoms such as asocialia (AOR $=4.327,95 \% \mathrm{CI}=1.980$ to 9.455$)$ and loss of personal motivation $(\mathrm{AOR}=3.462$, $95 \% \mathrm{CI}=1.528$ to 7.844 ), and having suicidal behaviour $(\mathrm{AOR}=6.834,95 \% \mathrm{CI}=3.240$ to 14.411$)$ were the significant predictors of unrecognised comorbid depression among PWS as shown in table 4.

\section{DISCUSSION}

The primary aim of this study was to determine the prevalence of unrecognised comorbid depression among PWS. This study found out that nearly one-third of PWS $(30.3 \%)$ has undiagnosed depression in a stable phase of the disease. This is in agreement with previous studies $30 \%$ in Egypt ${ }^{32} 27.2 \%$ in Greece ${ }^{33}$ and $31 \%$ in Spain. ${ }^{34}$ Similarly, a study among PWS living in a nursing home found out that more than one-fourth $(26.5 \%)$ were present with depression. ${ }^{27}$ However, higher prevalence $(56 \%)$ of depression was reported by Cardoso and his colleagues based on the CDSS among PWS. ${ }^{35}$ In addition, the prevalence of comorbid depressive symptoms was reported to be $40.6 \%-54.6 \%{ }^{36-38}$ in patients with Chinese chronic schizophrenia which is higher than our finding. This inconsistency might be explained by the fact that previous studies may have included some patients in the acute phase because the higher rate of depression is reported in the prodromal and acute phases compared with the stable phase of schizophrenia. ${ }^{39}$ Similarly, in this study, patients treated with antidepressants were excluding from the study too.

With respect to our overall theoretical model, we found that 13 categories of variables were significant in bivariate analysis and that only seven retained statistically significance in multiple logistic regression analysis. Patients who were living alone, having poor and moderate social support, non-adherence to medication presenting with current negative symptoms like asocialia and loss of personal motivation and having suicidal behaviour were identified as a number of variables that were associated with higher rates of unrecognised comorbid depression in people with schizophrenia.

Our study found out that depression rate of PWS who were living alone and had poor or moderate social support was quite higher as compared with their counterparts. This indicates that lack of family support and environmental conditions like having inadequate social support 
Table 4 Predictors of unrecognised depression on multivariate logistic regression analyses in PWS at AMSH, 2019

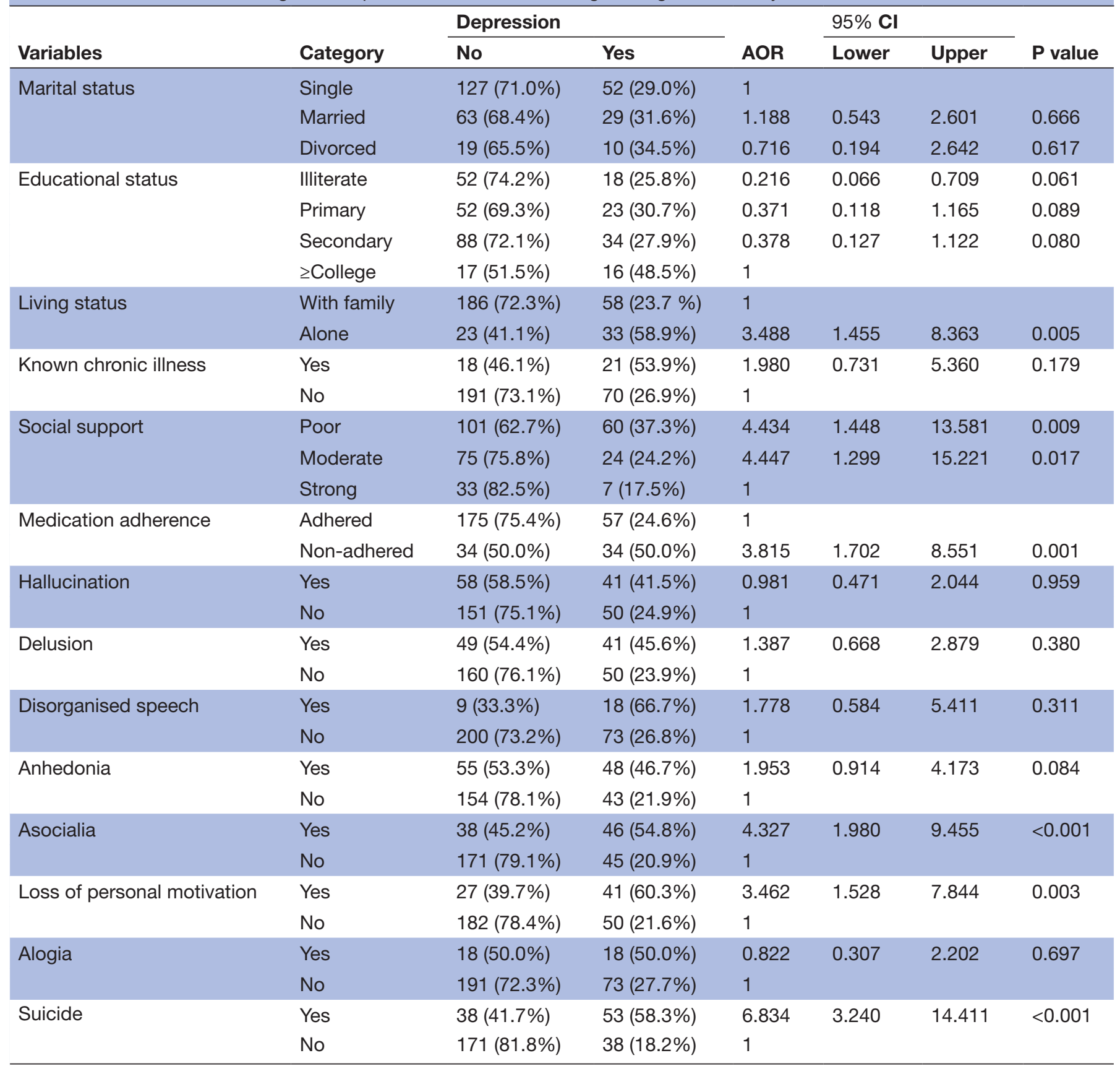

AMSH, Amanuel mental specialized hospital; AOR, adjusted OR; PWS, patients with schizophrenia.

could be important factors in the exhibition of depressive symptoms in PWS. ${ }^{27}$ In addition, social support is postulated to safeguard mental health through the benefits of social relationships and as a buffer against stressful conditions. ${ }^{40}$ Therefore, support from a spouse, relatives or friends is supposed to have independent protective effects against depression. ${ }^{414}$

Our results, consistent with the literature, found an association between having chronic physical illnesses and depression. ${ }^{43}$ In our study, patients with any type of chronic illnesses like diabetes, HIV/AIDS, cancer, hypertension and so on have two times more likely to have depression than those without chronic illnesses. Moreover, the interplay among physical illness and depression in PWS is probably bidirectional. ${ }^{44}$ Living with depression and a chronic physical illness can make life more complicated. It can make living harder to find the energy to work, exercise, interact with family members and friends or take medication regularly. ${ }^{45}$ This could make you feel isolated and make it firmer to get better from depression easily.

This study showed that people with schizophrenia who are non-adherent to their anti-psychotic medication were nearly four times at higher risk to develop depression. It 
is fact that patients who are adherent well to their treatment had decreased symptomatology and become functional socially and occupationally. This reduces stigma, increases self-esteem, and inspires hope in PWS, which indirectly reduces the risk of depression. Studies reported that depression could occur in antipsychotic-free PWS and the magnitude of significant depression decreases when antipsychotic treatment is started. ${ }^{46}$ In fact, several studies found out that antipsychotic medications do not seem to induce depressive syndromes in PWS. ${ }^{47}$ On the other hand, other reports tend to underline that neuroleptic medications are responsible for the development of depressive episodes in PWS. ${ }^{48}$

In our study, patients with negative symptoms that is, those who had asocialia and loss of personal motivation were more than four and three times greater risk of developing depression, respectively. This could be due to the fact that the conceptual overlap between depressive syndromes and negative symptoms. ${ }^{49}$ Furthermore, antipsychotic medications could have aetiological role in depressive symptomatology in schizophrenia associated with its action on dopaminergic pathways (play major role in reward and pleasure) and extra pyramidal sideeffect that causes 'akinetic depression'. ${ }^{39}$ There is no clear boundary between the two syndromes. However, it is fact that the presentations of the symptoms are different qualitatively and subjectively in the context of depression and negative symptoms.

Those PWS having suicidal behaviour were nearly seven times more likely to have depressive features. Similar to our finding, Gokhan et a $\tilde{l}^{0}$ found statistically significant higher CDSS average score in patients with suicidal ideations and wishes as compared with their counterparts. Nearly $10 \%$ of people with schizophrenia commit suicide, and most of them had history of depressive episodes or had presented with signs or symptoms of depression during their contacts with health workers. ${ }^{39}$

Even though, this study provided a baseline data, and we use a standardised tool (CDSS) designed to assess depression in PWS, it also has some limitations encountered. Exclusion of patients who were on antidepressant medications and studying only PWS in outpatients could have led to an underestimation of the prevalence of depression. Our study was a cross-sectional design that does not show cause and effect relationship also might be considered as limitation. It might be difficult to generalise the findings of this study due to the reason that this study was conducted using non-probability consecutive sampling method and small sample size. In addition, even though, we use internationally validated instrument to assess depression, CDSS was not yet validated in Ethiopia.

\section{CONCLUSION AND RECOMMENDATIONS}

Nearly one-third of PWS have undiagnosed depression in a stable phase of the disease. Therefore, the prevalence of unrecognised depression in this study was found to be $30.3 \%$. The likelihood of having unrecognised comorbid depression was higher among those living alone, and those having poor and moderate social support. Furthermore, non-adherence to medication, presenting with negative symptoms like asocialia and loss of personal motivation, and having suicidal behaviour were significantly associated with comorbid depression.

Therefore, we recommend clinicians better to strengthen early screening of comorbid depression among PWS and take early appropriate treatment measures in order to prevent or lessen the burden of depression on the treatment outcome of schizophrenia. Our key recommendation to psychiatrists and mental health professionals who treat PWS and depression is to perform a careful diagnostic assessment, which is essential to tailor appropriate treatments. From our results, we have firm grounds that those clinicians to initiate suitable psychosocial interventions and medications for PWS.

Acknowledgements We would like to acknowledge staffs of AMSH, data collectors and participants for their valuable participation in the study process.

Contributors MA and YR designed the study, involved in the data collection and analysis of the study. MA prepares the manuscript for publication, and YR and SD critically reviewed the manuscript. All authors read and approved the final manuscript.

Funding The authors have not declared a specific grant for this research from any funding agency in the public, commercial or not-for-profit sectors.

Competing interests None declared.

Patient and public involvement Patients and/or the public were not involved in the design, or conduct, or reporting, or dissemination plans of this research.

Patient consent for publication Consent obtained directly from patient(s)

Provenance and peer review Not commissioned; externally peer reviewed.

Data availability statement All data relevant to the study are included in the article or uploaded as supplementary information. All the datasets used and analysed during the current study are available on this manuscript.

Open access This is an open access article distributed in accordance with the Creative Commons Attribution Non Commercial (CC BY-NC 4.0) license, which permits others to distribute, remix, adapt, build upon this work non-commercially, and license their derivative works on different terms, provided the original work is properly cited, appropriate credit is given, any changes made indicated, and the use is non-commercial. See: http://creativecommons.org/licenses/by-nc/4.0/.

ORCID iDs

Mohammed Ayalew http://orcid.org/0000-0001-9973-5741

Yared Reta http://orcid.org/0000-0002-8509-2287

\section{REFERENCES}

1 World Health Organization. World Health organization. the global burden of disease: 2004 update. Geneva: World Health Organization, 2008.

2 Ekman M, Granstrom O, Omerov S, et al. The societal cost of schizophrenia in Sweden. J Ment Health Policy Econ 2013;16:13-25.

3 Whiteford HA, Degenhardt L, Rehm J, et al. Global burden of disease attributable to mental and substance use disorders: findings from the global burden of disease study 2010. Lancet 2013;382:1575-86.

4 Buckley PF, Miller BJ, Lehrer DS, et al. Psychiatric comorbidities and schizophrenia. Schizophr Bull 2009;35:383-402.

5 Siris SG BC. Depression and schizophrenia. 2nd ed. Hirsch SR WD, editor. Oxford, UK: Blackwell Publishing Ltd, 2003.

6 Dan A, Kumar S, Avasthi A, et al. A comparative study on quality of life of patients of schizophrenia with and without depression. Psychiatry Res 2011;189:185-9.

7 Siris SG. Diagnosis of secondary depression in schizophrenia: implications for DSM-IV. Schizophr Bull 1991;17:75-98.

8 Pokorski M, Warzecha A. Depression and religiosity in older age. Eur J Med Res 2011;16:401-6. 
9 Majadas S, Olivares J, Galan J, et al. Prevalence of depression and its relationship with other clinical characteristics in a sample of patients with stable schizophrenia. Compr Psychiatry 2012;53:145-51.

10 Balcı G, Oter G, Akdag H, et al. Factors associated with depression in patients with schizophrenia. JMOOD 2016;6:54-62.

11 Fenton WS, Depression FWS. Depression, suicide, and suicide prevention in schizophrenia. Suicide Life Threat Behav 2000;30:34-49.

12 Kilzieh N, Wood AE, Erdmann J, et al. Depression in Kraepelinian schizophrenia. Compr Psychiatry 2003;44:1-6.

13 Bowie C, Ph D, Anderson H. Depression in schizophrenia: methodological artifact or distinct feature of the illness? $J$ Neuropsychiatry Clin Neurosci 2009;20:431-40.

14 Siris SG. Depression in schizophrenia: perspective in the era of "Atypical" antipsychotic agents. Am J Psychiatry 2000;157:1379-89.

15 Möller H-J. Occurrence and treatment of depressive comorbidity/ cosyndromality in schizophrenic psychoses: conceptual and treatment issues. World J Biol Psychiatry 2005;6:247-63.

16 Rocca P, Bellino S, Calvarese P, et al. Depressive and negative symptoms in schizophrenia: different effects on clinical features. Compr Psychiatry 2005;46:304-10.

17 Addington D, Addington J, Patten S. Depression in people with firstepisode schizophrenia. Br J Psychiatry 1998;172:90-2.

18 Siris SG, Harmon GK, Endicott J. Postpsychotic depressive symptoms in hospitalized schizophrenic patients. Arch Gen Psychiatry 1981;38:1122-3.

19 Jeczmien P, Levkovitz Y, Weizman A, et al. Post-psychotic depression in schizophrenia. Isr Med Assoc J 2001;3:589-92.

20 Marengo J, Harrow M, Herbener ES, et al. A prospective longitudinal 10-year study of schizophrenia's three major factors and depression. Psychiatry Res 2000;97:61-77.

21 Liddle PF, Barnes TR, Curson DA, et al. Depression and the experience of psychological deficits in schizophrenia. Acta Psychiatr Scand 1993;88:243-7.

22 Siris SG. Akinesia and postpsychotic depression: a difficult differential diagnosis. J Clin Psychiatry 1987;48:240-3.

23 Bühler B, Hambrecht M, Löffler W, et al. Precipitation and determination of the onset and course of schizophrenia by substance abuse--a retrospective and prospective study of 232 populationbased first illness episodes. Schizophr Res 2002;54:243-51.

24 Hall RC, Gardner ER, Popkin MK, et al. Unrecognized physical illness prompting psychiatric admission: a prospective study. Am J Psychiatry 1981;138:629-35.

25 Castle D, Bosanac P. Depression and schizophrenia. Adv. psychiatr. treat 2012;18:280-8.

26 Haro JM, Kamath SA, Ochoa S, et al. The clinical global ImpressionSchizophrenia scale: a simple instrument to measure the diversity of symptoms present in schizophrenia. Acta Psychiatr Scand 2003;107:16-23.

27 Ertekin H, Er M, Ozayhan HY, et al. Quality of life and depression in schizophrenia patients living in a nursing home. J Psychiatry Neurol Sci 2015;28:213-21.

28 Addington D, Addington J, Maticka-Tyndale E. Specificity of the Calgary depression scale for schizophrenics. Schizophr Res 1994;11:239-44.

29 Bøen H, Dalgard OS, Bjertness E. The importance of social support in the associations between psychological distress and somatic health problems and socio-economic factors among older adults living at home: a cross sectional study. BMC Geriatr 2012;12:1-12.

30 Morisky DE, Green LW, Levine DM. Concurrent and predictive validity of a self-reported measure of medication adherence. Med Care 1986;24:67-74.
31 Osman A, Bagge CL, Gutierrez PM, et al. The suicidal behaviors Questionnaire-Revised (SBQ-R): validation with clinical and nonclinical samples. Assessment 2001;8:443-54.

32 El-Bahy M, Mohamed WMY. Prevalence of depression in schizophrenic patients evaluated by the Calgary depression scale in Shebin El-Kom, Menoufiya. Middle East Current Psychiatry 2013;20:191-6.

33 Skokou PG M. Depression in the active phase of paranoid schizophrenia in relation to age of onset and sex. Eur Psychiatry 2016;33S:S114-289.

34 Majadas S, Olivares J, Galan J, et al. Prevalence of depression and its relationship with other clinical characteristics in a sample of patients with stable schizophrenia. Compr Psychiatry 2012;53:145-51.

35 Cardoso CS, Caiaffa WT, Bandeira M, et al. [Depression in schizophrenia: prevalence and relationship to quality of life]. Cad Saude Publica 2007;23:2035-48.

36 Xu Y-M, Li F, Liu X-B, et al. Depressive symptoms in Chinese male inpatients with schizophrenia: prevalence and clinical correlates. Psychiatry Res 2018;264:380-4.

37 Dai J, Du X, Yin G, et al. Prevalence, demographic and clinical features of comorbid depressive symptoms in drug naïve patients with schizophrenia presenting with first episode psychosis. Schizophr Res 2018;193:182-7.

38 Liu LQ, Zhou P. Depressive symptoms in patients with chronic schizophrenia (in Chinese). J Clin Psychiatry 2009;19:34-6.

39 Mulholland $\mathrm{C}$, Cooper S. The symptom of depression in schizophrenia and its management. Adv. psychiatr. treat 2000;6:169-77.

40 Slavin LA, Rainer KL. Gender differences in emotional support and depressive symptoms among adolescents: a prospective analysis. Am J Community Psychol 1990;18:407-21.

41 Rubin C, Rubenstein JL, Stechler G, et al. Depressive affect in "normal" adolescents: relationship to life stress, family, and friends. Am J Orthopsychiatry 1992;62:430-41.

42 Patten CA, Gillin JC, Farkas AJ, et al. Depressive symptoms in California adolescents: family structure and parental support. $J$ Adolesc Health 1997;20:271-8.

43 Diwan S, Cohen CI, Bankole AO, Vahia I, Kehn M, et al. Depression in older adults with schizophrenia spectrum disorders: prevalence and associated factors. Am J Geriatr Psychiatry 2007;15:991-8.

44 Koenig HG, George LK. Depression and physical disability outcomes in depressed medically ill hospitalized older adults. Am J Geriatr Psychiatry 1998;6:230-47.

45 Cohen M, Quintner J, Buchanan DN, M, et al. Stigmatisation of patients with chronic pain: the extinction of empathy. Pain Med 2011.

46 Baynes D, Mulholland C, Cooper SJ, et al. Depressive symptoms in stable chronic schizophrenia: prevalence and relationship to psychopathology and treatment. Schizophr Res 2000;45:47-56.

47 Gaur V, Jagawat T, Dhanda A, et al. Depression in schizophrenia: correlation with psychopathology nd level of functioning. Delhi Psychiatry J 2014;17:83-8.

48 Buckley PF, Miller BJ, Lehrer DS, et al. Psychiatric comorbidities and schizophrenia. Schizophr Bull 2009;35:383-402.

49 Siris SG, Adan F, Cohen M, et al. Postpsychotic depression and negative symptoms: an investigation of syndromal overlap. $A m \mathrm{~J}$ Psychiatry 1988;145:1532-7.

50 Umut G, Altun ZO, Danismant BS, et al. The correlation of suicide attempt and suicidal ideation with insight, depression and severity of illness in schizophrenic patients. Dusunen Adam 2013;26:341-50. 